\title{
Obesity and the risk of primary liver cancer: A system- atic review and meta-analysis
}

Won Sohn ${ }^{1, *}$, Hyun Woong Lee, ${ }^{2, *}$, Sangheun Lee ${ }^{3}$, Jin Hong Lim ${ }^{4}$, Min Woo Lee ${ }^{5}$, Chan Hyuk Park ${ }^{6}$, and Seung Kew Yoon ${ }^{7}$

'Division of Gastroenterology, Department of Internal Medicine, Kangbuk Samsung Hospital, Sungkyunkwan University School of Medicine, Seoul; ' Department of Internal Medicine, Gangnam Severance Hospital, Yonsei University College of Medicine, Seoul; ${ }^{3}$ Department of Internal Medicine, International St. Mary's Hospital, Catholic Kwandong University College of Medicine, Incheon; ${ }^{4}$ Department of General Surgery, Gangnam Severance Hospital, Yonsei University College of Medicine, Seoul; ${ }^{5}$ Department of Radiology and Center for Imaging Science, Samsung Medical Center, Sungkyunkwan University School of Medicine, Seoul; ${ }^{6}$ Department of Internal Medicine, Hanyang University Guri Hospital, Hanyang University College of Medicine, Guri; ${ }^{7}$ Department of Internal Medicine, Seoul St. Mary's Hospital, The Catholic University College of Medicine, Seoul, Korea

\section{Graphical Abstract}

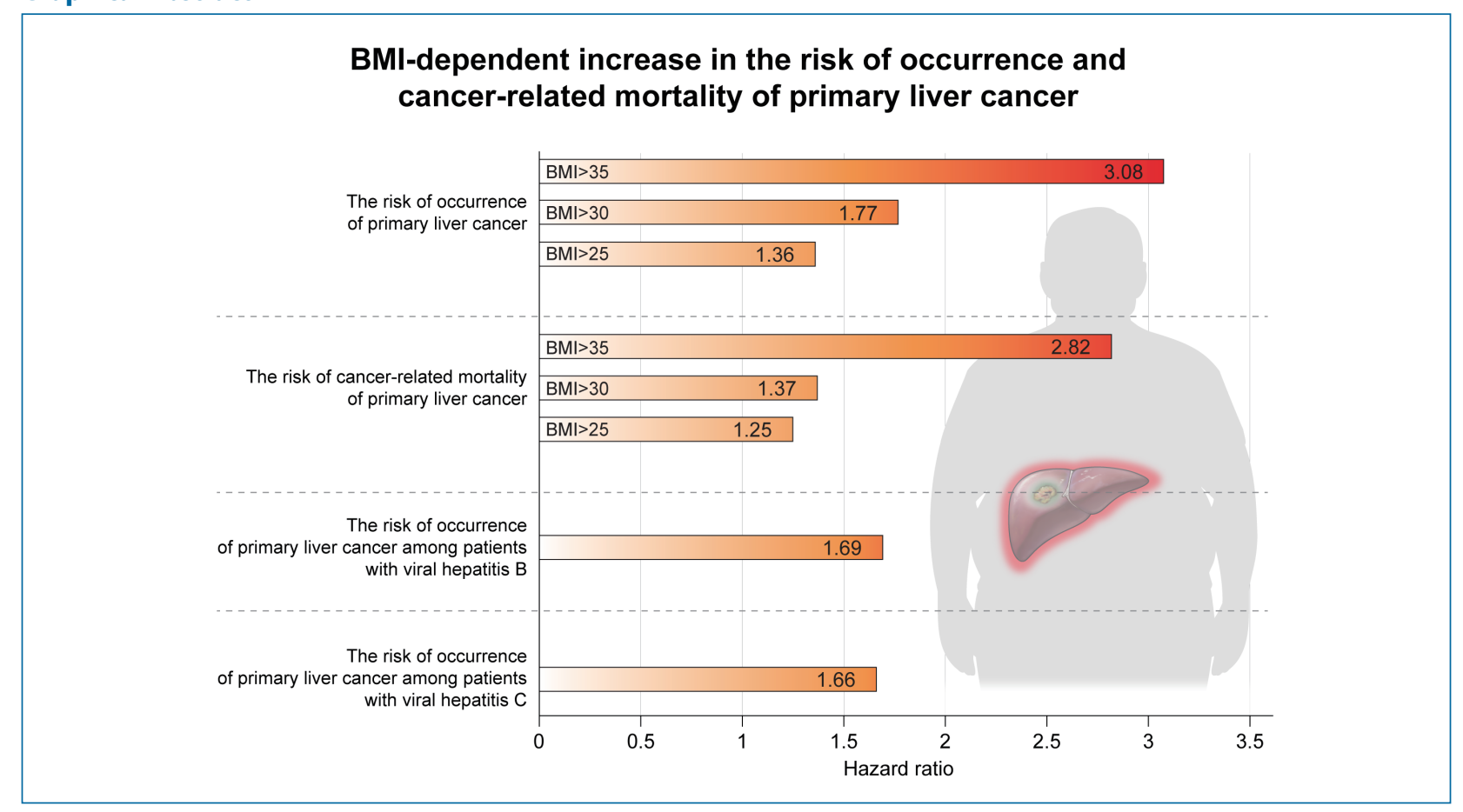

\section{Abbreviations:}

$\mathrm{BMI}$, body mass index; $\mathrm{Cl}$, confidence interval; $\mathrm{HCC}$, hepatocellular carcinoma; HRs, hazard ratios; NAFLD, nonalcoholic fatty liver disease; OR, odds ratio; RR, relative risk
Corresponding author: Seung Kew Yoon

Department of Internal Medicine, Seoul St. Mary's Hospital, The Catholic University College of Medicine, 222 Banpo-daero, Seocho-gu, Seoul 06591, Korea

Tel: +82-2-2258-1425, Fax: +82-2-3481-4025

E-mail:yoonsk@catholic.ac.kr

https://orcid.org/0000-0002-4476-4868

*These authors contributed equally to this work. 
Background/Aims: In this systematic review and meta-analysis, we aimed to clarify the effect of obesity on the occurrence of and mortality from primary liver cancer.

Methods: This study was conducted using a systematic literature search of MEDLINE, EMBASE, and the Cochrane Library until November 2018 using the primary keywords "obesity," "overweight," "body mass index (BMI)," "body weight," "liver," "cancer," "hepatocellular carcinoma," "liver cancer," "risk," and "mortality." Studies assessing the relationship between $\mathrm{BMI}$ and occurrence of or mortality from primary liver cancer in prospective cohorts and those reporting hazard ratios (HRs) or data that allow HR estimation were included.

Results: A total of 28 prospective cohort studies with 8,135,906 subjects were included in the final analysis. These included 22 studies with 6,059,561 subjects for cancer occurrence and seven studies with 2,077,425 subjects for cancerrelated mortality. In the meta-analysis, an increase in BMI was associated with the occurrence of primary liver cancer (HR, $1.69 ; 95 \%$ confidence interval, $\left.1.50-1.90, I^{2}=56 \%\right)$. A BMI-dependent increase in the risk of occurrence of primary liver cancer was reported. HRs were $1.36(95 \% \mathrm{Cl}, 1.02-1.81), 1.77(95 \% \mathrm{Cl}, 1.56-2.01)$, and $3.08(95 \% \mathrm{Cl}, 1.21-7.86)$ for $\mathrm{BMI}>25$ $\mathrm{kg} / \mathrm{m}^{2},>30 \mathrm{~kg} / \mathrm{m}^{2}$, and $>35 \mathrm{~kg} / \mathrm{m}^{2}$, respectively. Furthermore, increased BMl resulted in enhanced liver cancer-related mortality (HR, $\left.1.61 ; 95 \% \mathrm{Cl}, 1.14-2.27, \mathrm{l}^{2}=80 \%\right)$.

Conclusions: High BMI increases liver cancer mortality and occurrence of primary liver cancer. Obesity is an independent risk factor for the occurrence of and mortality from primary liver cancer. (Clin Mol Hepatol 2021;27:157-174)

Keywords: Obesity; Liver cancer; Carcinoma, Hepatocellular; Risk; Mortality

\section{Study Highlights}

1. An increase in BMI was associated with the occurrence of primary liver cancer (HR, 1.69).

2. A BMI-dependent occurrence of primary liver cancer was reported. HRs were $1.36,1.77$, and 3.08 for $\mathrm{BMl}>25 \mathrm{~kg} / \mathrm{m}^{2},>30 \mathrm{~kg} / \mathrm{m}^{2}$, and $>35 \mathrm{~kg} / \mathrm{m}^{2}, \mathrm{re}-$ spectively.

3. Increased BMI resulted in enhanced liver cancer-related mortality (HR, 1.61).

4. Obesity is an independent risk factor for the occurrence of and mortality from primary liver cancer.

\section{INTRODUCTION}

Obesity is an abnormal condition characterized by excessive accumulation of body fat. In general, high body mass index (BMI) is indicative of obesity. The prevalence of obesity and excess weight has increased, accounting for more than a third of the world's population in recent years.' Obesity underlies conditions such as cardiovascular disease, hypertension, diabetes mellitus, nonalcoholic fatty liver disease (NAFLD), gallbladder disease, pancreatitis, sleep apnea, and osteoarthritis. ${ }^{2}$ These diseases lead to chronic disability in obese people. Obesity is also an independent factor for the development of various cancers ${ }^{3}$ and is closely associated with cancer regardless of age, sex, race, and type of cancer. ${ }^{4}$ Cancer-related mortality is high in obese patients with prostate cancer, breast cancer, and colorectal cancer. ${ }^{5}$

Primary liver cancer is one of the most common malignancies and the associated mortality rate corresponds to $9 \%$ of all cancerrelated deaths worldwide. ${ }^{6}$ Hepatocellular carcinoma (HCC) is the most common type of primary liver cancer and accounts for approximately $80-90 \%$ of all cases of primary liver cancer. The common causes of HCC are viral hepatitis (hepatitis B or C virus), alcohol, smoking, and diabetes mellitus.?

Studies have been conducted to investigate whether obesity is a risk factor for the occurrence of primary liver cancer. Some studies have found that obesity is a risk factor for HCC occurrence, while Chen et al. reported a lack of association between obesity and HCC occurrence. ${ }^{8-10}$ However, studies suggesting the relationship between obesity and primary liver cancer may suffer from risk of bias because they were conducted as case-control or retrospective cohort studies. Hence, the present study was conducted to analyze prospective cohorts to determine the relationship between BMI and primary liver cancer. We aimed to clarify the effect of obesity on the occurrence of and mortality from primary liver cancer using systematic review and meta-analysis. 


\section{MATERIALS AND METHODS}

\section{Search strategy}

We searched for all relevant studies published from January 1990 to November 2018 that investigated the relationship between obesity and risk of primary liver cancer. We used MEDLINE, EMBASE, and Cochrane Library databases. The fundamental concept of the data search for the systematic review and meta-analysis was as follows: (obesity) OR (obese) OR (overweight) OR (body weight) OR (body mass index) AND (hepatocellular carcinoma) OR ([liver] AND [cancer] AND ['risk' OR 'mortality']). However, there were slight differences in the detailed searching methods among the three databases, as each database has its own search formula. The detailed search methods used for each database are described in the Supplementary Material 1. Further, reference lists of the searched articles were checked to identify additional studies. All human studies written in English were examined, and the latest date for searching the relevant studies was November 8, 2018.

\section{Study selection}

First, we checked the titles and abstracts of the selected papers to exclude irrelevant articles. Second, the complete text of all selected researches was reviewed based on the inclusion and exclusion criteria. The inclusion criteria were: 1) patients: the subjects who participated in the studies on primary liver cancer; 2) intervention: obesity; 3) comparator: non-obese subjects; 4) outcome: occurrence or cancer-related mortality of primary liver cancer including HCC; and 5) study design: prospective cohort study. We excluded irrelevant studies according to the following criteria: 1) publications in a language other than English; 2) abstract-only publications or unpublished studies; 3) non-original articles; and 4) animal studies. In case of overlapping cohorts, we included only one study that had the largest number of subjects and excluded the other studies. In this meta-analysis, we included studies that presented hazard ratios (HRs) estimated using Cox proportional hazards model, because this model is suitable for analyzing cancer occurrence and cancer-related mortality. Previous meta-analyses for the relationship between obesity and primary liver cancer were reported before 2012. ${ }^{11-13}$ The present study included original studies published after 2012 in addition to the studies included in the previous meta-analyses. However, among the studies included in the previous meta-analyses, we excluded several retrospective studies, overlapping cohort studies, and studies that were not analyzed using Cox proportional hazard model. The eligibility of the studies was independently assessed by two reviewers (W. Sohn and S. Lee). In case of disagreement, we re-reviewed the studies and determined whether they were relevant for the final analysis based on discussion and consensus. A third investigator (H.W. Lee) determined the eligibility if the suitability of a study could not be determined even after re-evaluation.

A formal quality assessment of studies was performed to understand the risk of bias in each study. The methodological quality of the studies was independently evaluated by two investigators (W. Sohn and S. Lee) using the Newcastle-Ottawa scale for observational study. ${ }^{14}$ The scoring scale comprised three categories, namely, selection (four questions), comparability of study groups (two questions), and ascertainment of exposure or outcome (three questions). A cumulative score of more than 7 was reflective of the high quality of the study. ${ }^{15-17}$

\section{Data extraction}

Two reviewers (W. Sohn and S. Lee) independently extracted the necessary information and filled up the data form for analysis. The variables for the analysis were author, region, publication year, study period, definition of overweight or obesity according to $B M I$, number of subjects, hepatitis B virus status, hepatitis $C$ virus status, use of alcohol, diabetes mellitus, and the parameters adjusted in each study.

The primary endpoint was the occurrence of primary liver cancer, including HCC. We assessed the primary endpoint as HR with 95\% confidence interval ( $\mathrm{Cl}$ ) by comparing the subjects with/ without obesity or being overweight. The secondary end point was liver cancer-related mortality and was evaluated by HR with $95 \% \mathrm{Cl}$.

\section{Statistical analysis}

Meta-analyses were performed to calculate pooled HRs with $95 \% \mathrm{Cls}^{18}{ }^{18}$ A random effect model was used in the meta-analysis. Subgroup analysis was performed according to cut-off values of $\mathrm{BMI}$ because the definitions of obesity were different from each other. Obesity group was defined based on cut-off values of BMI: $>35 \mathrm{~kg} / \mathrm{m}^{2},>30 \mathrm{~kg} / \mathrm{m}^{2}$, and $>25 \mathrm{~kg} / \mathrm{m}^{2}$. We categorized obesity group of the studies with cut-off values of BMI $>27.5 \mathrm{~kg} / \mathrm{m}^{2}$ and $>27 \mathrm{~kg} / \mathrm{m}^{2}$ as obesity group with a cut-off value of BMI $>25 \mathrm{~kg} / \mathrm{m}^{2}$, because there was only a small number of studies with these cut- 
off values of. We also performed subgroup analyses according to ethnic group (Asian vs. non-Asian) and viral hepatitis (hepatitis B virus or hepatitis $C$ virus). Statistical heterogeneity was assessed using $I^{2}$ statistics, with values $>50 \%$ suggestive of significant heterogeneity. ${ }^{19}$ Publication bias was examined using the Egger's regression test ${ }^{20}$ and was also qualitatively assessed by inspecting funnel plots of the logarithmic HR versus their standard errors. ${ }^{21}$ The test for funnel plot asymmetry was not conducted if the included studies were fewer than $10 .{ }^{22}$ To assess the effect of mean age and male proportion of study participants on the effect size, meta-regression analysis based on a random-effects model was performed. All $P$-values were two-tailed, and a value of $P<0.05$ was considered statistically significant in all tests (except for the heterogeneity and Egger's regression tests). Analysis and reporting were performed according to the Preferred Reporting Items for Systematic Reviews and Meta-Analyses guidelines. ${ }^{23}$ All statistical procedures were conducted using the statistical software Review Manager 5.3 (version 5.3.5; Cochrane Collaboration, Copenhagen, Denmark), with the exception of the meta-regression and publication bias analyses, which were performed using $\mathrm{R}$ (version 4.0.2; R Foundation for Statistical Computing, Vienna, Austria).

\section{RESULTS}

\section{Study selection}

A flow diagram of our literature search is shown in Figure 1. In summary, 4,108 studies were evaluated in our literature search and 1,055 duplicate articles were excluded from the three search engines. In addition, 2,840 other irrelevant articles were excluded based on the titles and abstracts. Two reviewers independently evaluated the complete text of the 213 remaining articles for their eligibility. Thereafter, 185 articles were excluded for the following reasons: study did not report relevant outcomes ( $n=140)$, nonprospective studies ( $n=17)$, abstract only ( $n=11)$, non-original articles $(n=9)$, cohort overlap between studies $(n=7)$, and non-cohort studies $(n=1)$. Finally, 28 studies with $8,135,906$ subjects were se-
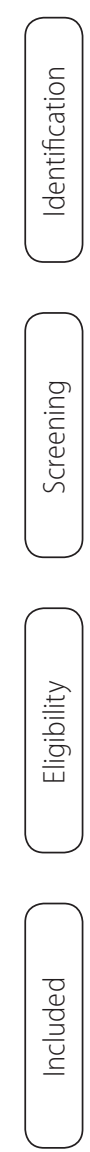
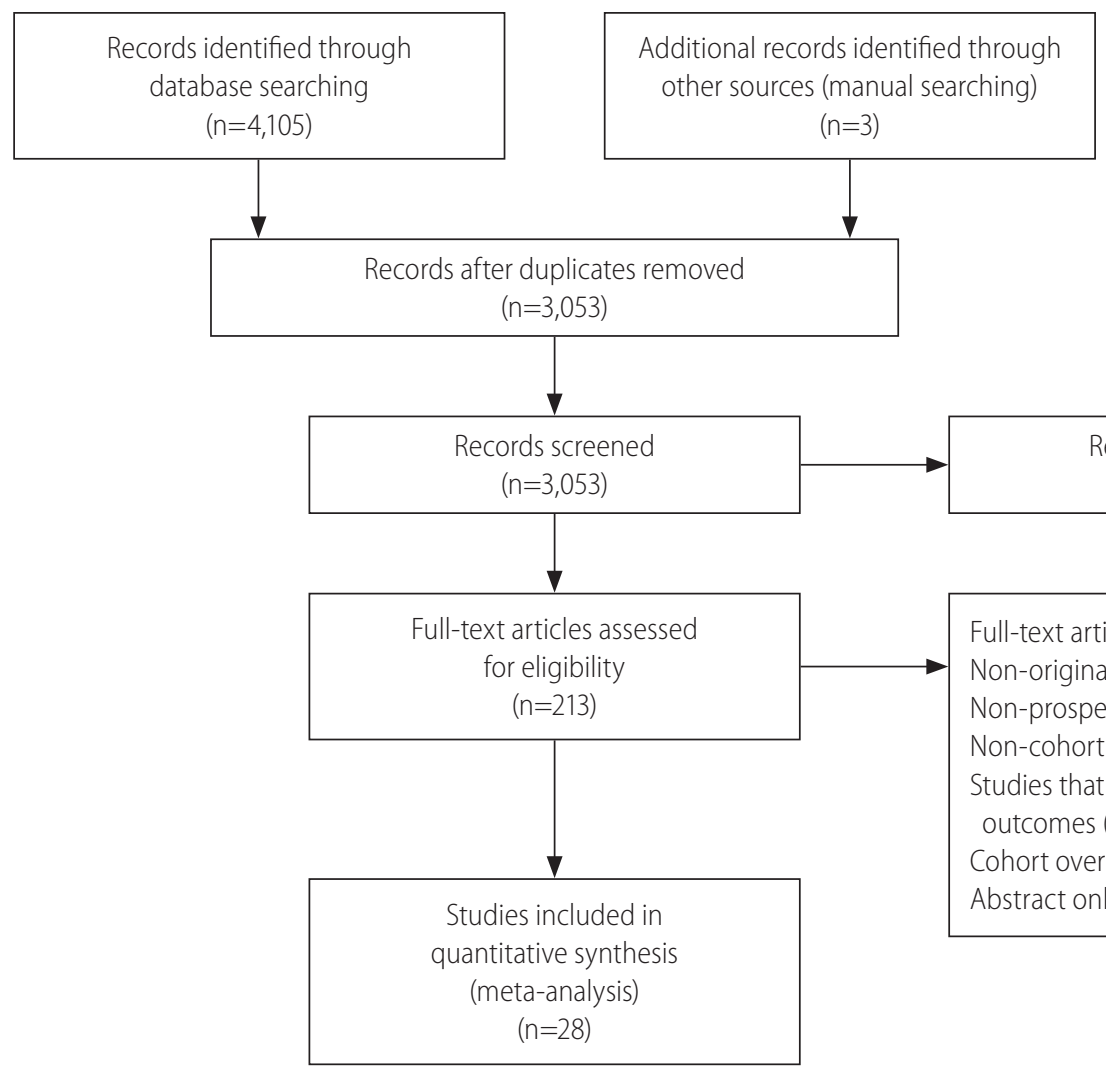

Full-text articles excluded: Non-original articles $(n=9)$ Non-prospective studies $(n=17)$ Non-cohort studies $(n=1)$ Studies that did not report relevant outcomes $(n=140)$ Cohort overlap between studies $(n=7)$ Abstract only $(n=11)$

Figure 1. Flow diagram of the studies included in the meta-analysis. 
lected for the systematic review and meta-analysis. ${ }^{24-51}$

\section{Study characteristics}

The characteristics of the included studies for meta-analysis are described in Table 1. These studies were published between 2003 and 2018, and the enrollment period ranged from 1972 to 2013. The regions where the studies were conducted included the USA $(n=5)$, Europe $(n=10)$, and Asia $(n=13)$. According to the Newcastle-Ottawa scale, $79 \%$ (22/28) of the studies were deemed to be of high quality (score $\geq 7$ ).
Table 2 shows the clinical characteristics of the subjects in the included studies. Seven studies reported clinical outcomes (primary or secondary endpoint) separately only based on sex. Therefore, we considered these studies as different reports and performed the meta-analysis based on the population of men and women. The obesity group was defined based on a BMI of $>35$ $\mathrm{kg} / \mathrm{m}^{2}$ in four studies, $>30 \mathrm{~kg} / \mathrm{m}^{2}$ in 23 studies, $>27.5 \mathrm{~kg} / \mathrm{m}^{2}$ in two studies, $>27 \mathrm{~kg} / \mathrm{m}^{2}$ in one study, and $>25 \mathrm{~kg} / \mathrm{m}^{2}$ in five studies. While HRs for liver cancer occurrence were reported in 26 studies, those for cancer-related mortality were reported in 10 studies. One study showed HRs for both the occurrence of and

Table 1. Characteristics of the studies included in the meta-analysis

\begin{tabular}{|c|c|c|c|c|c|c|c|}
\hline \multirow{2}{*}{ Study } & \multirow{2}{*}{ Region } & \multirow{2}{*}{ Study period } & \multirow{2}{*}{ Number of subjects } & \multirow{2}{*}{ Male (\%) } & \multicolumn{3}{|c|}{ Newcastle-Ottawa scale } \\
\hline & & & & & Selection & Comparability & Outcome \\
\hline Calle et al. ${ }^{24}$ (2003) & USA & 1982-1988 & 900,053 & 45.0 & $* * * *$ & * & $* * *$ \\
\hline Batty et al. ${ }^{25}$ (2005) & UK & $1967-2002$ & 18,403 & 100.0 & $* * *$ & * & ** \\
\hline Kuriyama et al. ${ }^{26}$ (2005) & Japan & 1984-1992 & 27,539 & 45.3 & $* * *$ & * & $* *$ \\
\hline Rapp et al. $^{27}$ (2005) & Austria & $1985-2002$ & 145,931 & 46.2 & $* * *$ & * & $* *$ \\
\hline N'Kontchou et al..$^{28}$ (2006) & France & 1994-2004 & 771 & 64.3 & $* * * *$ & $* *$ & * \\
\hline Jee et al. ${ }^{29}$ (2008) & Korea & 1992-2006 & $1,213,829$ & 63.5 & $* * *$ & * & * \\
\hline Joshi et al. ${ }^{30}$ (2008) & Korea & $1998-2004$ & 548,530 & 100.0 & $* * *$ & $* *$ & $* *$ \\
\hline Inoue et al. ${ }^{31}$ (2009) & Japan & 1993-2006 & 17,590 & 34.6 & $* * * *$ & $* *$ & ** \\
\hline Wang et al. ${ }^{32}$ (2009) & Taiwan & 1997-2004 & 5,929 & 43.5 & $* * *$ & ** & $* *$ \\
\hline Hart et al..$^{33}$ (2010) & Scotland & $1965-2007$ & 26,738 & 61.8 & $* * * *$ & * & $* * *$ \\
\hline Chao et al. ${ }^{34}$ (2011) & Taiwan & 1989-2006 & 1,142 & 100.0 & $* * * *$ & ** & $* * *$ \\
\hline Hung et al. ${ }^{35}$ (2011) & Taiwan & 1999-2009 & 1,470 & 52.1 & **** & ** & $* * *$ \\
\hline Borena et al. ${ }^{36}$ (2012) & Europe & $1972-2006$ & 578,700 & 50.1 & $* * * *$ & * & $* * *$ \\
\hline Chen et al. ${ }^{37}$ (2013) & Taiwan & 2004-2007 & 56,231 & 30.9 & $* * * *$ & $* *$ & ** \\
\hline Li et al. ${ }^{38}(2013)$ & Japan & 1988-2009 & 72,473 & 42.8 & $* * * *$ & * & $* * *$ \\
\hline Loomba et al. ${ }^{39}$ (2013) & Taiwan & 1991-2004 & 23,712 & 50.3 & $* * * *$ & $* *$ & $* * *$ \\
\hline Song et al. ${ }^{40}$ (2014) & Europe & $1972-2008$ & 54,725 & 48.7 & $* * * *$ & * & $* * *$ \\
\hline Meyer et al..$^{41}$ (2015) & Europe & $1977-2008$ & 35,784 & 47.2 & $* * * *$ & * & ** \\
\hline Campbell et al. ${ }^{42}$ (2016) & USA & $1980-2011$ & $1,570,023$ & 40.8 & $* * *$ & * & ** \\
\hline Liu et al. ${ }^{43}$ (2016) & China & $1996-2013$ & 68,253 & 0.0 & $* * * *$ & * & $* *$ \\
\hline Setiawan et al. ${ }^{44}$ (2016) & USA & $1993-2010$ & 168,476 & 46.3 & $* * * *$ & * & $* * *$ \\
\hline McMahon et al. ${ }^{45}$ (2017) & USA & $1995-2012$ & 1,080 & 49.3 & **** & $* *$ & $* *$ \\
\hline Nderitu et al. ${ }^{46}$ (2017) & Sweden & $1985-2011$ & 65,224 & 57.2 & $* * * *$ & * & $* *$ \\
\hline Yang et al. ${ }^{47}$ (2017) & USA & 1995-2011 & 297,928 & 58.5 & *** & * & ** \\
\hline Brichler et al. ${ }^{48}$ (2019) & France & $2006-2012$ & 317 & 82.3 & $* * * *$ & $* *$ & $* *$ \\
\hline Hagström et al. ${ }^{49}$ (2018) & Sweden & $1969-2012$ & $1,220,261$ & 100.0 & $* * * *$ & * & ** \\
\hline Jeong et al..$^{50}(2018)$ & Korea & $2002-2013$ & 510,148 & 54.3 & $* * * *$ & * & $* * *$ \\
\hline Yi et al..$^{51}(2018)$ & Korea & $2002-2013$ & 504,646 & 54.3 & $* * * *$ & $* *$ & $* *$ \\
\hline
\end{tabular}




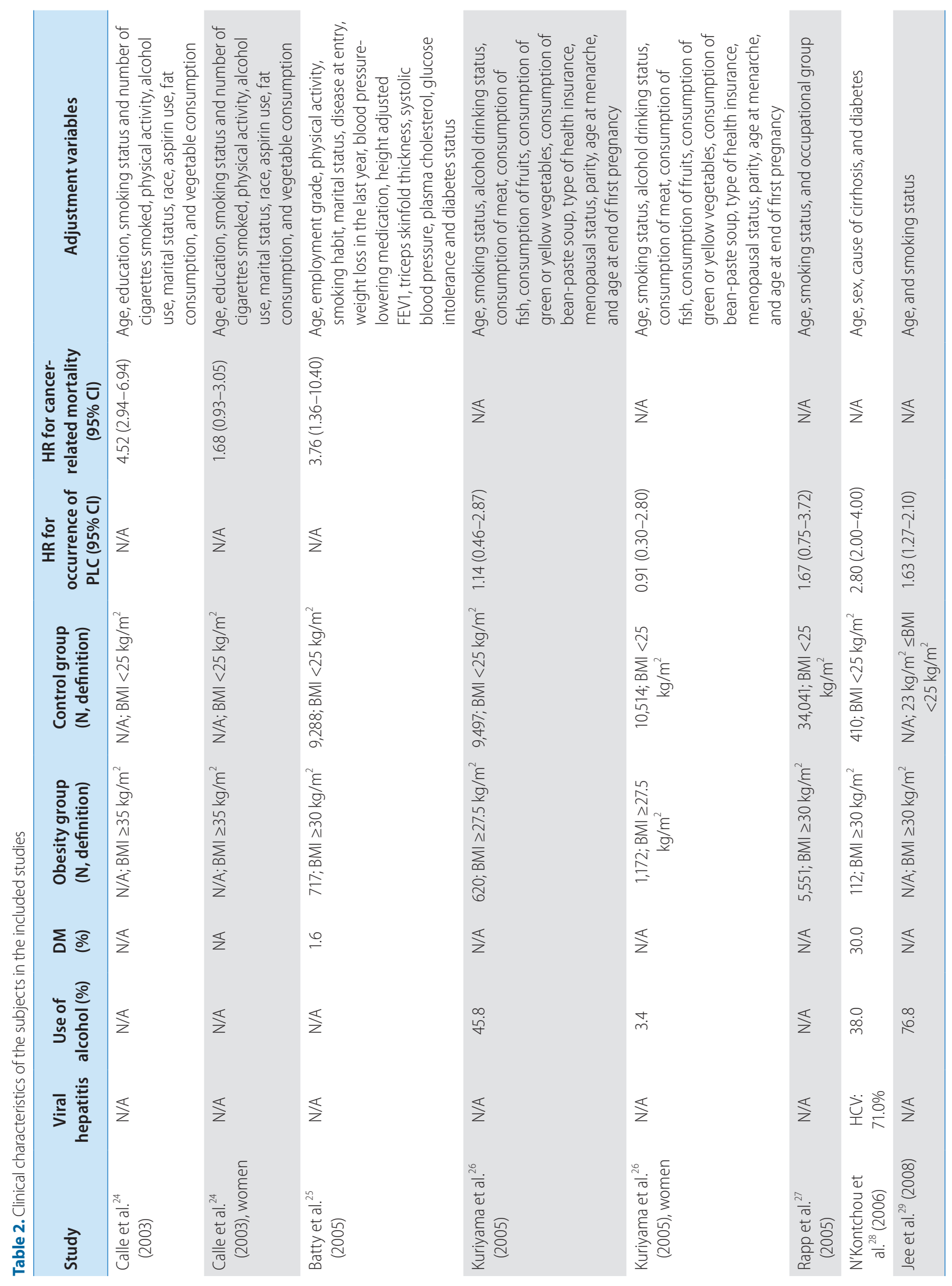




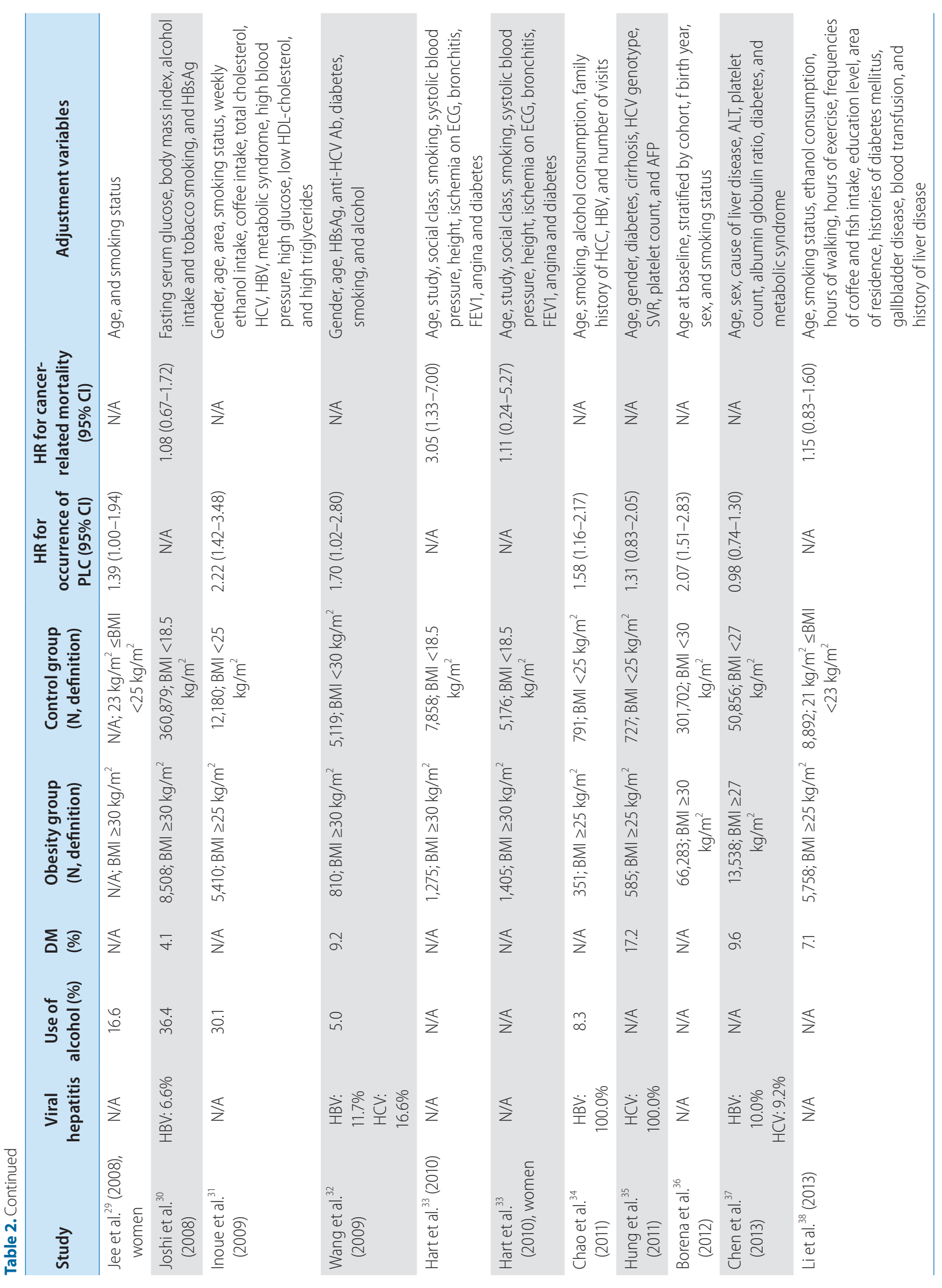




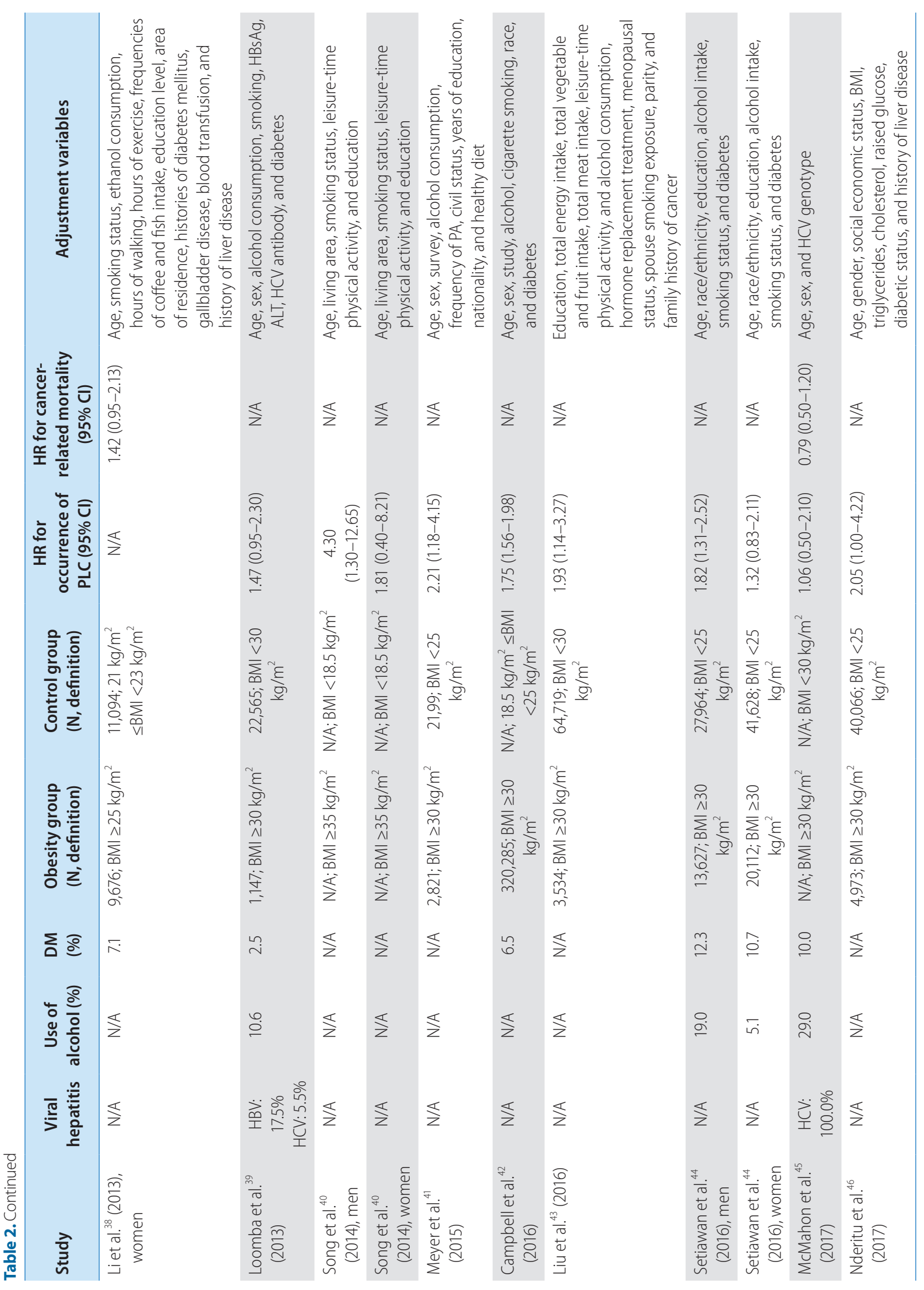


Won Sohn, et al.

Obesity and primary liver cancer risk

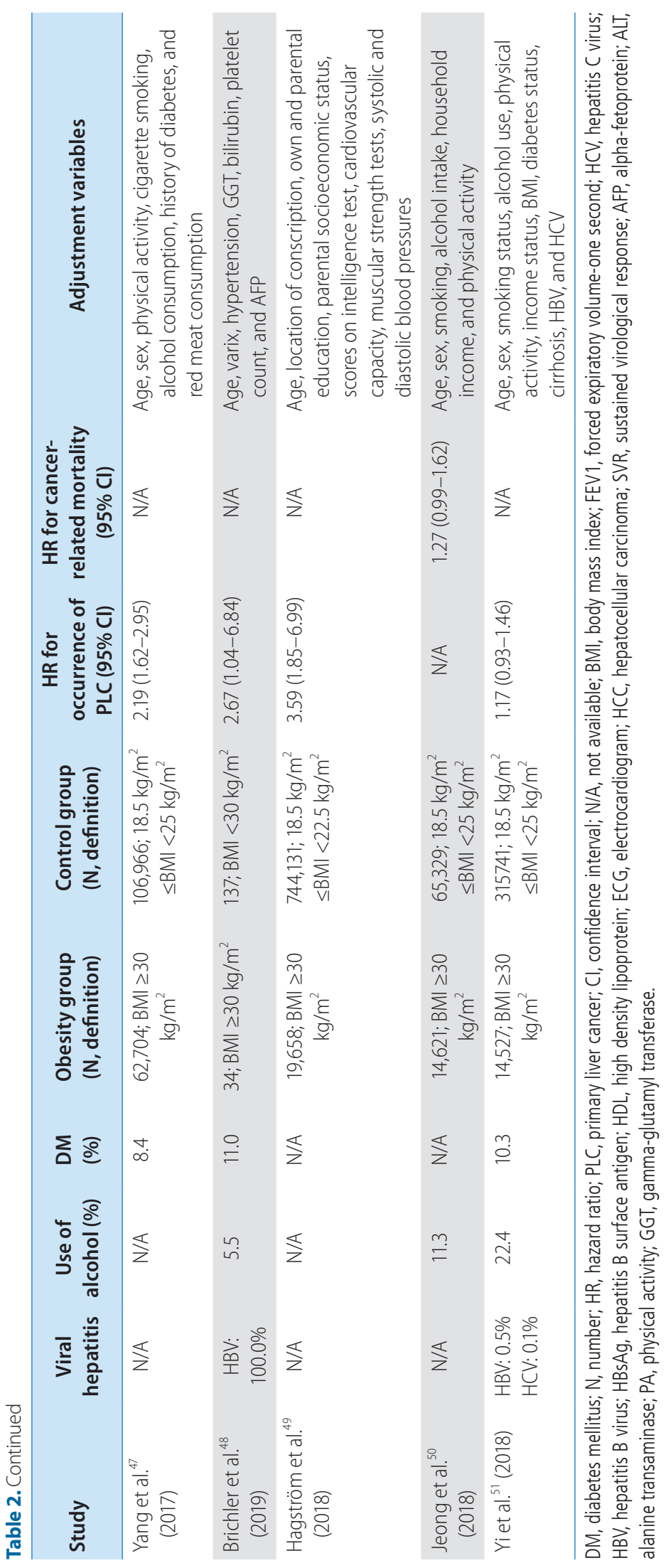




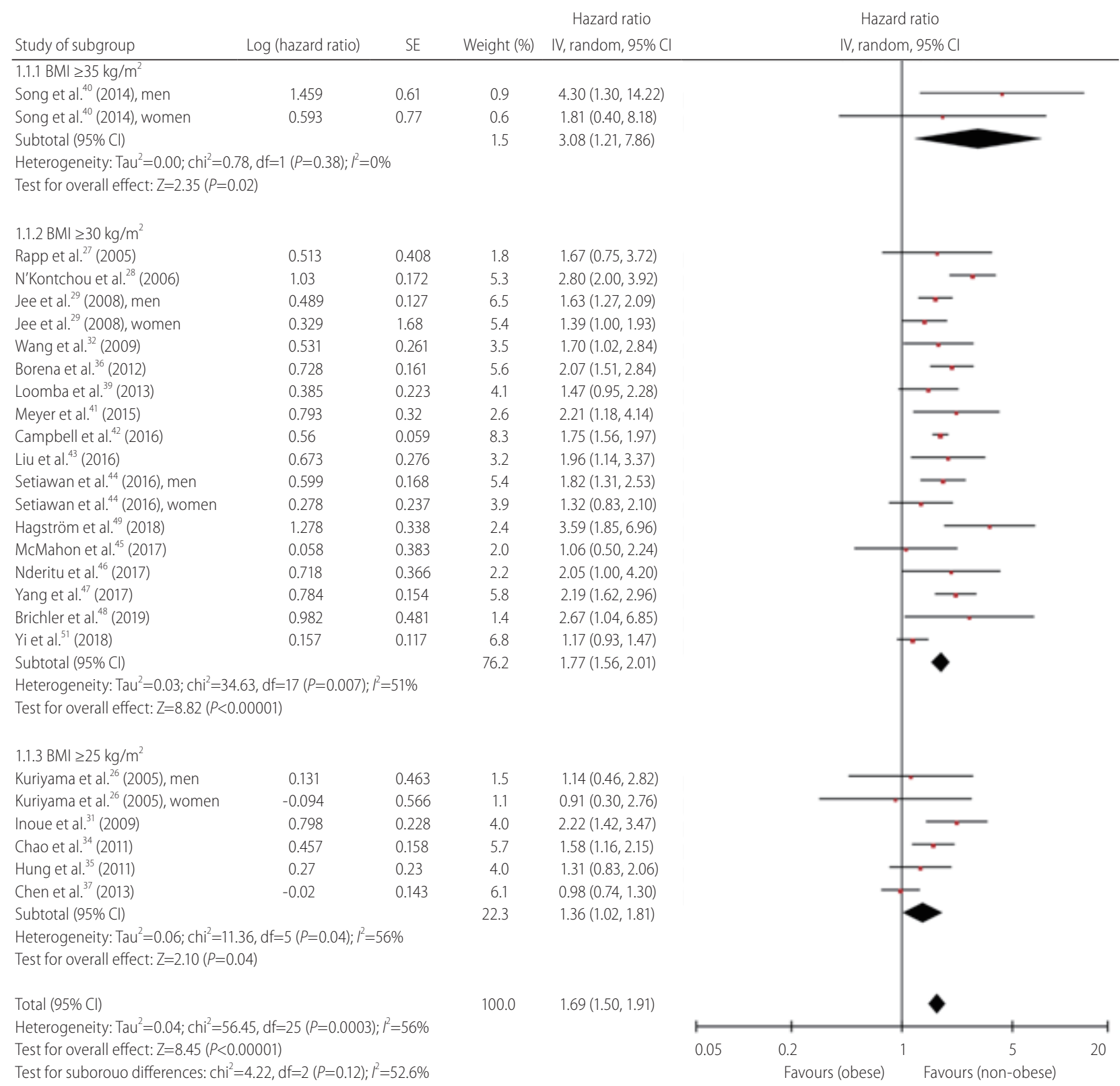

A

Figure 2. Forest plots of all the studies analyzing the occurrence (A) and cancer-related mortality (B) from primary liver cancer. SE, standard error; Cl, confidence interval; BMl, body mass index.

mortality from primary liver cancer. ${ }^{45}$ The adjustable variables for primary or secondary endpoint were factors such as age, sex, alcohol, and smoking.

\section{Occurrence of and cancer-related mortality from primary liver cancer}

Figure 2 indicates the meta-analysis of the occurrence of and mortality from primary liver cancer in the included studies. The pooled HR for the occurrence of primary liver cancer was 1.69 (95\% Cl, 1.50-1.9, I'=56\%) (Fig. 2A). A BMI-dependent increase in the risk of occurrence of primary liver cancer was reported. The values of $\mathrm{HRs}$ were $1.36(95 \% \mathrm{Cl}, 1.02-1.81), 1.77(95 \% \mathrm{Cl}$, $1.56-2.01)$, and $3.08(95 \% \mathrm{Cl}, 1.21-7.86)$ for $\mathrm{BMI}>25 \mathrm{~kg} / \mathrm{m}^{2}$, $>30 \mathrm{~kg} / \mathrm{m}^{2}$, and $>35 \mathrm{~kg} / \mathrm{m}^{2}$, respectively. The value of pooled HR was $1.61\left(95 \% \mathrm{Cl}, 1.14-2.27, I^{2}=80 \%\right)$ for cancer-related mortali- 


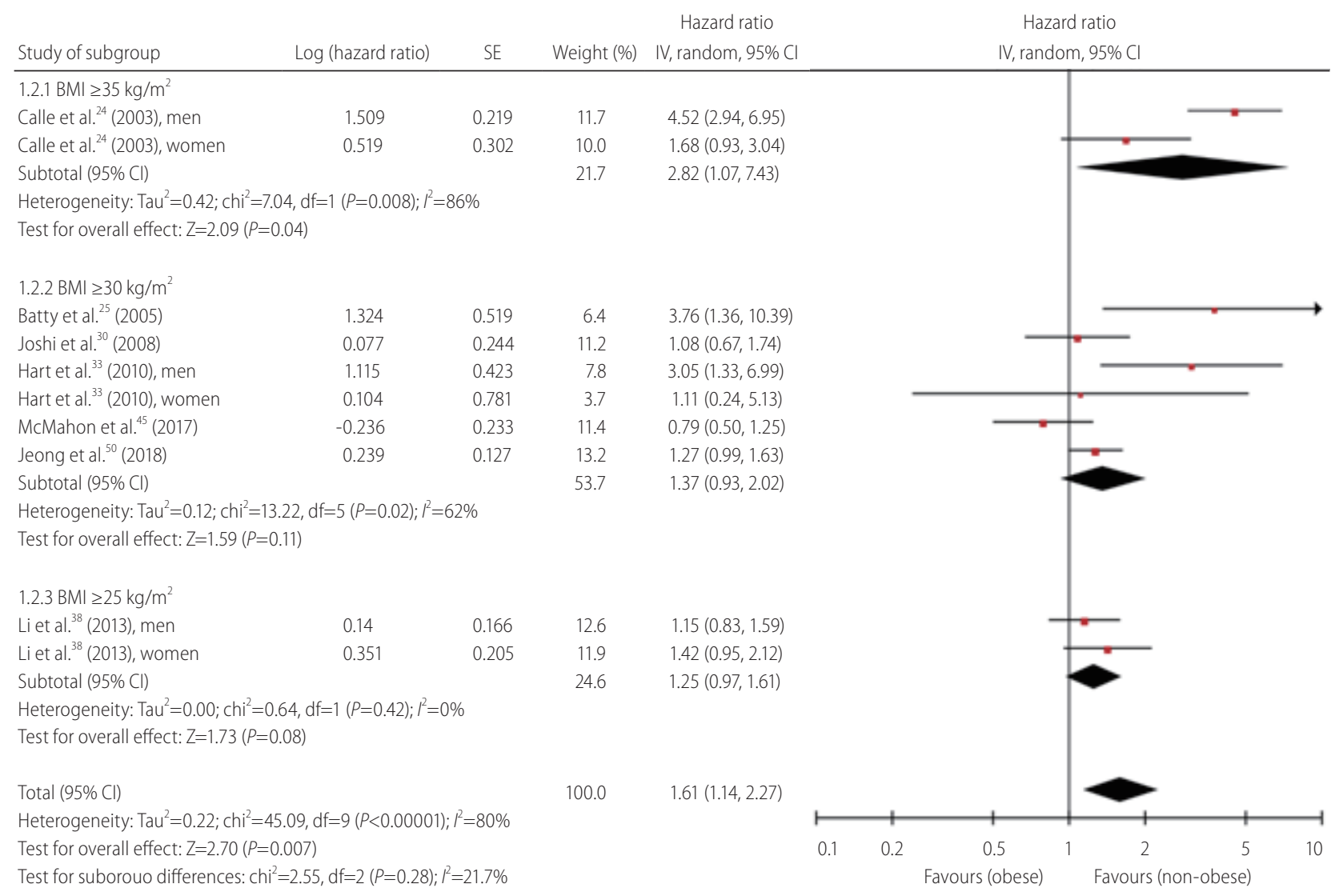

B

Figure 2. Continued.

ty of primary liver cancer (Fig. 2B). A relationship seemed to exist between $\mathrm{BMI}$ and mortality from primary liver cancer. The values of HRs were $1.25(95 \% \mathrm{Cl}, 0.97-1.61)$, $1.37(95 \% \mathrm{Cl}, 0.93-2.02)$, and $2.82(95 \% \mathrm{Cl}, 1.07-7.43)$ for $\mathrm{BMI}>25 \mathrm{~kg} / \mathrm{m}^{2},>30 \mathrm{~kg} / \mathrm{m}^{2}$, and $>35 \mathrm{~kg} / \mathrm{m}^{2}$, respectively.

Primary and secondary endpoints were evaluated for Asian subjects and non-Asian subjects (Fig. 3). The pooled HR for the occurrence of primary liver cancer was $1.42(95 \% \mathrm{Cl}, 1.23-1.63$, $I^{2}=37 \%$ ) (Fig. 3A) among Asian subjects. A BMI-dependent increase in the risk of occurrence of primary liver cancer was observed in Asian subjects; the HR values were 1.36 (95\% Cl, 1.021.82) and $1.44(95 \% \mathrm{Cl}, 1.24-1.67)$ for $\mathrm{BMI}>25$ and $>30 \mathrm{~kg} / \mathrm{m}^{2}$, respectively. Among Asian subjects, the pooled HR was 1.24 $\left(95 \% \mathrm{Cl}, 1.05-1.46, I^{2}=0 \%\right)$ for mortality from primary liver cancer (Fig. 3B); the HR values were $1.25(95 \% \mathrm{Cl}, 0.97-1.61)$ and $1.23(95 \% \mathrm{Cl}, 0.98-1.53)$ for $\mathrm{BMI}>25$ and $>30 \mathrm{~kg} / \mathrm{m}^{2}$, respectively. The pooled HR for the occurrence of primary liver cancer was $2.00\left(95 \% \mathrm{Cl}, 1.73-2.31, I^{2}=32 \%\right)$ among non-Asian sub- jects (Fig. 3C). A BMI-dependent increase in the risk of occurrence of primary liver cancer was also observed in non-Asian subjects; the $\mathrm{HR}$ values were $1.98(95 \% \mathrm{Cl}, 1.71-2.29)$ and $3.08(95 \% \mathrm{Cl}$, $1.21-7.86)$ for $\mathrm{BMI}>30$ and $>35 \mathrm{~kg} / \mathrm{m}^{2}$, respectively. Among nonAsian subjects, the pooled HR was $2.10(95 \% \mathrm{Cl}, 1.03-4.26$, $\left.I^{2}=85 \%\right)$ for mortality from primary liver cancer (Fig. 3D); the HR values were $1.75(95 \% \mathrm{Cl}, 0.71-4.31)$ and $2.82(95 \% \mathrm{Cl}, 1.07-$ 7.43) for $\mathrm{BMI}>30$ and $>35 \mathrm{~kg} / \mathrm{m}^{2}$, respectively. We also assessed cancer occurrence in five studies on patients with viral hepatitis (hepatitis B virus or hepatitis C virus), which is a high-risk population for primary liver cancer (Supplementary Fig. 1). The HR for cancer occurrence in patients with viral hepatitis was 1.76 (95\% $\left.\mathrm{Cl}, 1.22-2.54, I^{2}=66 \%\right)$, and this value was higher than that reported for the whole population. A BMI-dependent increase in the risk of occurrence of primary liver cancer among patients with viral hepatitis was observed (Supplementary Fig. 1A); the HR values were $1.49(95 \% \mathrm{Cl}, 1.15-1.92)$ and $2.07(95 \% \mathrm{Cl}, 1.11-3.85)$ for $\mathrm{BMI}>25$ and $>30 \mathrm{~kg} / \mathrm{m}^{2}$, respectively. 


\section{CLINCAL and MOLECULAR}

Volume_27 Number_1 January 2021

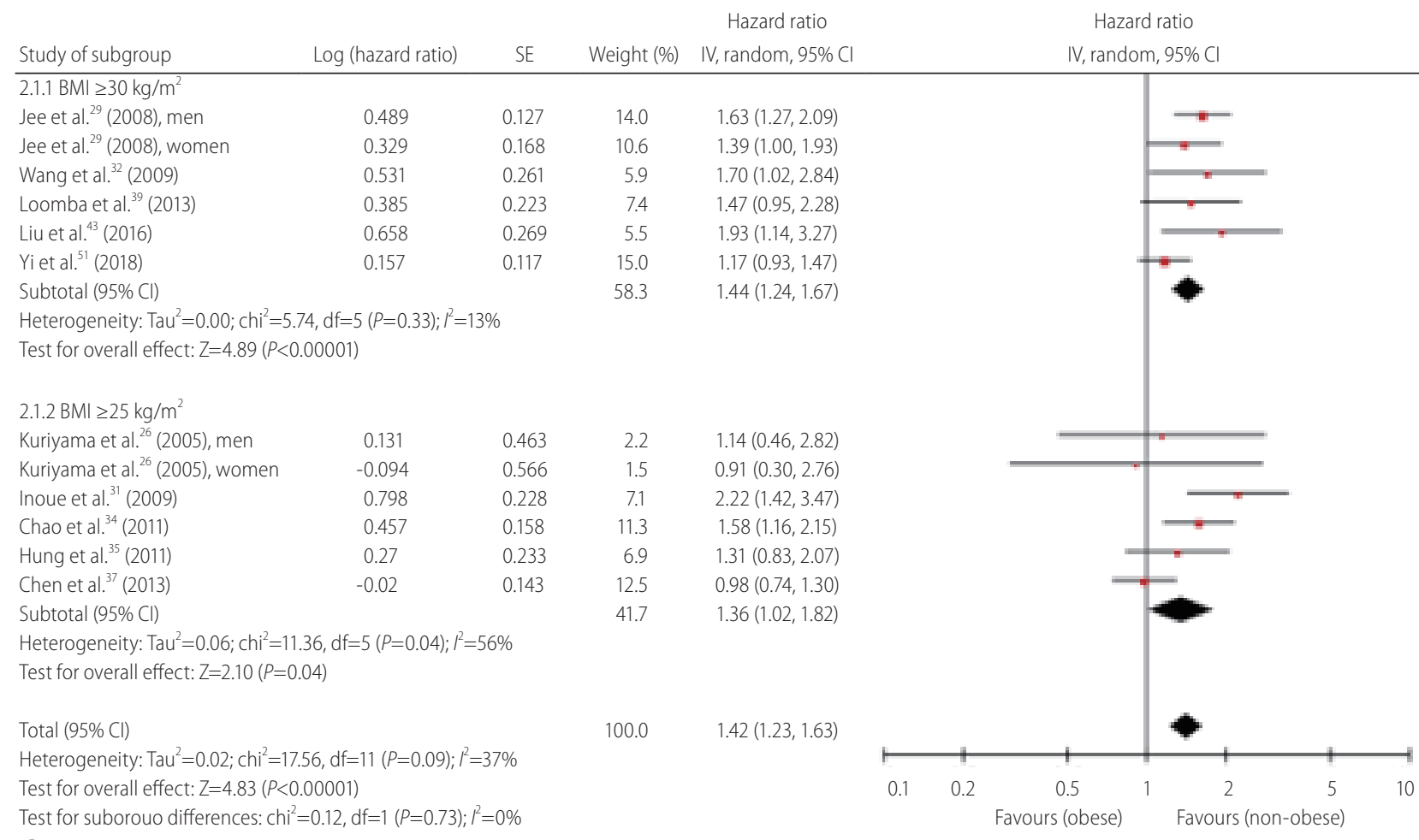

A

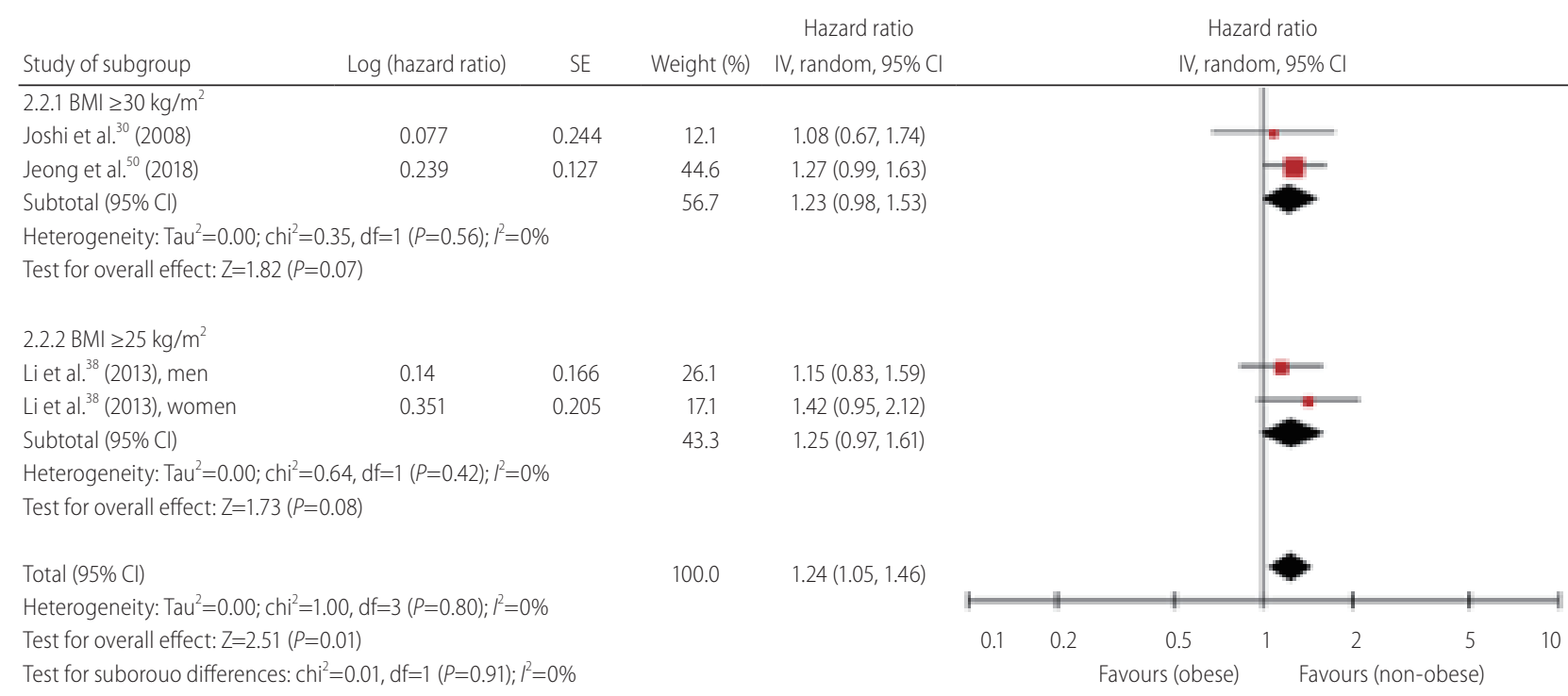

B

Figure 3. Subgroup analysis according to ethnic group (Asian vs. non-Asian): the occurrence of $(A, C)$ and cancer-related mortality ( $B, D)$ from primary liver cancer in Asian subjects (A, B) and non-Asian subjects (C, D). SE, standard error; Cl, confidence interval; BMI, body mass index. 
Won Sohn, et al. Obesity and primary liver cancer risk

Hazard ratio

\begin{tabular}{|c|c|c|c|c|}
\hline Study of subgroup & Log (hazard ratio) & SE & Weight (\%) & IV, random, $95 \%$ \\
\hline \multicolumn{5}{|l|}{$2.3 .1 \mathrm{BMI} \geq 35 \mathrm{~kg} / \mathrm{m}^{2}$} \\
\hline Song et al..$^{40}(2014)$, men & 1.459 & 0.61 & 1.4 & $4.30(1.30,14.2$ \\
\hline Song et al. ${ }^{40}(2014)$, women & 0.593 & 0.77 & 0.9 & $1.81(0.40,8.18)$ \\
\hline Subtotal $(95 \% \mathrm{Cl})$ & & & 2.2 & $3.08(1.21,7.86)$ \\
\hline \multicolumn{5}{|c|}{ Heterogeneity: $\operatorname{Tau}^{2}=0.00 ; \mathrm{chi}^{2}=0.78, \mathrm{df}=1(P=0.38) ; l^{2}=0 \%$} \\
\hline \multicolumn{5}{|c|}{ Test for overall effect: $Z=2.35(P=0.02)$} \\
\hline \multicolumn{5}{|l|}{ 2.3.2 $\mathrm{BMI} \geq 30 \mathrm{~kg} / \mathrm{m}^{2}$} \\
\hline Rapp et al. ${ }^{27}(2005)$ & 0.513 & 0.406 & 2.9 & $1.67(0.75,3.72)$ \\
\hline N'Kontchou et al. ${ }^{28}$ (2006) & 1.03 & 0.172 & 11.0 & $2.80(2.00,3.9$ \\
\hline Borena et al. ${ }^{36}(2012)$ & 0.728 & 0.161 & 11.9 & $2.07(1.51,2.8$ \\
\hline Meyer et al..$^{41}(2015)$ & 0.793 & 0.32 & 4.4 & $2.21(1.18,4.14)$ \\
\hline Campbell et al. ${ }^{42}(2016)$ & 0.56 & 0.059 & 23.9 & $1.75(1.56,1.9$ \\
\hline Setiawan et al. ${ }^{44}$ (2016), men & 0.599 & 0.168 & 11.3 & $1.82(1.31,2.53)$ \\
\hline Setiawan et al. ${ }^{44}$ (2016), wemen & 0.278 & 0.237 & 7.1 & $1.32(0.83,2.10)$ \\
\hline Hagström et al. ${ }^{49}$ (2018) & 1.278 & 0.338 & 4.0 & $3.59(1.85,6.9$ \\
\hline McMahon et al..$^{45}(2017)$ & 0.058 & 0.383 & 3.2 & $1.06(0.50,2.2$ \\
\hline Nderitu et al..$^{46}(2017)$ & 0.718 & 0.366 & 3.5 & $2.05(1.00,4.2$ \\
\hline Yang et al. ${ }^{47}(2017)$ & 0.784 & 0.154 & 12.5 & $2.19(1.62,2.9$ \\
\hline Brichler et al. ${ }^{48}(2019)$ & 0.982 & 0.481 & 2.1 & $2.67(1.04,6.8$ \\
\hline Subtotal $(95 \%$ Cl) & & & 97.8 & $1.98(1.71,2.2$ \\
\hline
\end{tabular}

Heterogeneity: $\operatorname{Tau}^{2}=0.02 ; \mathrm{chi}^{2}=17.26, \mathrm{df}=11(P=0.10) ;{ }^{2}=36 \%$

Test for overall effect: $Z=9.18(P<0.00001)$

Total $(95 \%$ Cl)

Heterogeneity: $\operatorname{Tau}^{2}=0.02 ; \mathrm{chi}^{2}=19.09, \mathrm{df}=13(P=0.12) ; P^{2}=32 \%$

Test for overall effect: $Z=9.50(P<0.00001)$

Test for suborouo differences: $\mathrm{chi}^{2}=0.83, \mathrm{df}=1(P=0.36) ; P^{2}=0 \%$

$2.00(1.73,2.31)$

C

Hazard ratio Hazard ratio

Study of subgroup

Log (hazard ratio)

SE

Weight (\%) IV, random, 95\% C

IV, random, $95 \% \mathrm{Cl}$

$2.4 .1 \mathrm{BMl} \geq 35 \mathrm{~kg} / \mathrm{m}^{2}$

Calle et al..$^{24}$ (2003), men

1.509

$0.219 \quad 19.8$

$4.52(2.94,6.95)$

Calle et al..$^{24}(2003)$, women

0.519

0.302

18.6

$1.68(0.93,3.04)$

Subtotal $(95 \% \mathrm{Cl})$

38.4

$2.82(1.07,7.43)$

Heterogeneity: $\mathrm{Tau}^{2}=0.42 ; \mathrm{chi}^{2}=7.04, \mathrm{df}=1(P=0.0006) ;{ }^{2}=86 \%$

Test for overall effect: $Z=2.09(P=0.04)$

2.4.2 BMI $\geq 30 \mathrm{~kg} / \mathrm{m}^{2}$

Batty et al. ${ }^{25}(2005)$

Hart et al. ${ }^{33}$ (2010), men

1.324

0.519

Hart et al..$^{33}$ (2010), women

1.115

0.423

14.8

$3.76(1.36,10.39)$

McMahon et al..$^{45}$ (2017)

0.104

0.781

16.5

$3.05(1.33,6.99)$

$-0.236$

0.233

Subtotal $(95 \% \mathrm{Cl})$

10.7

$1.11(0.24,5.13)$

$0.79(0.50,1.25)$

Heterogeneity: $\operatorname{Tau}^{2}=0.61 ; \mathrm{Chi}^{2}=12.84, \mathrm{df}=3(P=0.005) ;{ }^{2}=77 \%$

Test for overall effect: $Z=1.22(P=0.22)$

Total $(95 \% \mathrm{Cl})$

Heterogeneity: $\operatorname{Tau}^{2}=0.61 ; \mathrm{Chi}^{2}=33.11, \mathrm{df}=5(P<0.00001) ;{ }^{P}=85 \%$ Test for overall effect: $Z=2.05(P=0.04)$

Test for suborouo differences: $\mathrm{ch}^{2}{ }^{2}=0.50, \mathrm{df}=1(P=0.48) ;{ }^{2}=0 \%$
Hazard ratio

IV, random, $95 \% \mathrm{Cl}$

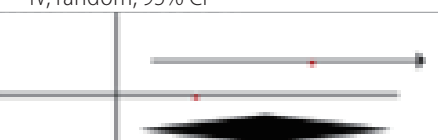

$1.75(0.71,4.31)$

100.0

$2.10(1.03,4.26)$

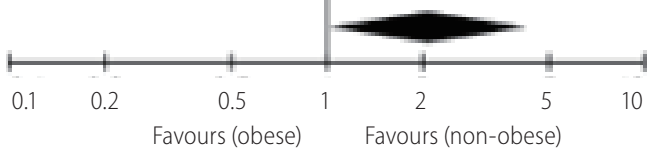

D

Figure 3. Continued. 


\section{Publication bias}

Egger's regression test showed no significant publication bias in cancer occurrence and cancer-related mortality in the whole population ( $P=0.652$ and $P=0.490$, respectively). Furthermore, no asymmetry was observed on visual inspection of the funnel plots (Supplementary Fig. 2).

\section{Meta-regression analysis}

Supplementary Figure 3 shows the results of meta-regression analysis for predicting HR for incidence or mortality according to mean age of the included studies. The mean age in each study was not associated with the risk of primary liver cancer occurrence or mortality (increased HR per 1 year-old of age: incidence, 0.998 [95\% Cl, 0.976-1.021]; mortality, 1.021 [0.965-1.079]). There was no significant difference in the relationship between obesity and the occurrence of and mortality from primary liver cancer according to age. As shown in Supplementary Figure 4, the proportion of males was also not associated with the risk of primary liver cancer occurrence or mortality (increased HR per one percentage of male proportion: incidence, $1.003[95 \% \mathrm{Cl}, 0.998-$ 1.009]; mortality, 1.004 [0.996-1.013]). There was no significant difference in the relationship between obesity and the occurrence of and mortality from primary liver cancer according to sex.

\section{DISCUSSION}

The present systematic review and meta-analysis were conducted to clarify whether obesity is an independent risk factor for the occurrence of and mortality from primary liver cancer. A total of 28 prospective cohort studies were finally included for the analysis. Obesity is defined based on BMI, and the findings of this study indicate that a high BMI value increases the risk of occurrence of and mortality from primary liver cancer. Furthermore, a BMI-dependent increase was observed for the risk of the occurrence of and mortality from primary liver cancer.

According to the World Health Organization report, an estimated 2.8 million people die each year worldwide owing to excess weight or obesity and 35.8 million global disability-adjusted life years result from by excess weight and obesity. ${ }^{52}$ The risk for developing cardiovascular diseases such as coronary heart disease and cerebrovascular disease and metabolic diseases such as type 2 diabetes mellitus consistently increase with an increase in BMI.
The increased BMI raises the risk of cancers of the breast, colon, prostate, endometrium, kidney, and gall bladder. ${ }^{52}$

Mechanisms of hepatocarcinogenesis in obesity are thought to be as follows: First, the liver is a major organ for fat storage. Proinflammatory cytokines (i.e., tumor necrosis factor-alpha and interleukin-6) secreted by the adipose tissue are oncogenic signaling mediators of liver cancer. ${ }^{53}$ The pro-inflammatory action of adipokines (i.e., leptin) and lipotoxicity induce carcinogenesis through proliferation or oncogenic mutations as well as inflammatory response. ${ }^{54}$ Second, insulin resistance or hyperinsulinemia is an important feature of cell proliferation accompanied with obesity. ${ }^{55}$ Finally, obesity induces changes in the gut microbiome that contribute to carcinogenesis. For instance, deoxycholic acid induced by intestinal microbiome leads to DNA damage and influences cancer development in obese mice. ${ }^{56}$

However, the role of obesity as a risk factor of primary liver cancer is not clearly understood through clinical data, although NAFLD, a disease that develops in response to increased BMI, is a cause of primary liver cancer. The most common etiology of primary liver cancer is chronic hepatitis B or C infection and chronic alcohol consumption, while NAFLD-related primary liver cancer only affects a small percentage of patients. ${ }^{57}$ In recent years, obesity has gained attention as a risk factor of primary liver cancer, owing to an increase in its prevalence. Many studies including few meta-analyses have evaluated the effect of obesity on the risk of primary liver cancer. However, the findings of these studies may involve a risk of bias because most of them were conducted using retrospective cohorts as case-control studies. There exist some differences in the evaluation of the risk of cancer in each study, including relative risk (RR), odds ratio (OR), and HR. Moreover, the OR-related RR was considered the same as HR-related RR in some meta-analyses. Hence, this systematic review and meta-analysis included only prospective cohort studies that reported HR, which is useful when the risk is not constant with respect to time.

The main finding of this study is that high BMI increases the occurrence of primary liver cancer. In particular, a BMI-dependent increase in the risk of occurrence of primary liver cancer was reported with pooled HRs of $1.36,1.77$, and 3.08 for $\mathrm{BMI}>25$, $>30$, and $>35 \mathrm{~kg} / \mathrm{m}^{2}$, respectively. This finding is consistent with that reported in previous meta-analyses. ${ }^{11-13}$ The previous metaanalyses were conducted based on the original studies before 2012. The present meta-analysis included original studies after 2012 in addition to the studies included in the previous metaanalyses. Therefore, we performed a meta-analysis for cancer occurrence and cancer-related mortality according to the publication 
year of the included studies (before 2012/after 2012). The results are shown in Supplementary Figure 5. The pooled HR for the occurrence of primary liver cancer in subjects with BMI $>30 \mathrm{~kg} / \mathrm{m}^{2}$ in the studies before and after the publication year 2012 was 1.85 $\left(95 \% \mathrm{Cl}, 1.49-2.30, I^{2}=52 \%\right)$ and $1.73(95 \% \mathrm{Cl}, 1.47-2.04$, $\left.I^{2}=53 \%\right)$, respectively. These results were consistent with those of the included studies regardless of the publication year. The secondary endpoint of this study was the mortality related to primary liver cancer. An increase in BMI was found to correlate with a rise in liver cancer-related mortality. Thus, obesity increases liver cancer-related mortality as well as the risk of occurrence of primary liver cancer.

The criteria of obesity in Asian people are different from those in Western people. ${ }^{58}$ We evaluated the differences in the effect of obesity on primary liver cancer in Asian and non-Asian subjects. Among Asian subjects, an increase in BMI resulted in a rise in the occurrence of and mortality related to primary liver cancer. Moreover, this study showed that high BMI increases cancer occurrence and cancer-related mortality in subjects with hepatitis B or C, which are high-risk groups for primary liver cancer. Considering these findings, obesity may serve as an independent factor for the occurrence and cancer-related mortality regardless of region and viral hepatitis.

This study has several limitations. First, it included studies that reported BMI as a categorical variable. We could not include those studies that reported the relationship between clinical outcomes and BMI as a continuous variable because it is not possible to integrate both categorical and continuous variables. Second, obesity was defined based on BMI. Obesity may be assessed more accurately if body fat measurement was carried out using other methods such as bioelectrical impedance analysis. Finally, this study showed that the risk of the occurrence of and mortality from primary liver cancer increased as BMI increased $\left(>25 \mathrm{~kg} / \mathrm{m}^{2}\right)$. However, low BMI was associated with poor prognosis in patients with liver disease other than liver cancer. Yi et al. ${ }^{59}$ reported that the mortality from alcoholic liver disease was significantly high in male subjects with lower BMI $\left(<21 \mathrm{~kg} / \mathrm{m}^{2}\right)$. Further studies are needed to clarify the diverse effect of BMI on the prognosis in patients with liver disease considering etiology, sex, and alcohol consumption. In spite of these limitations, the findings established herein provide evidence for the effect of obesity on primary liver cancer based on prospective cohort studies.

In conclusion, high BMI increases liver cancer mortality and occurrence of primary liver cancer. Obesity is an independent risk factor for the occurrence of and mortality associated with primary liver cancer.

\section{Authors' contribution}

Dr. Sohn, Dr. HW Lee, and Dr. Yoon have full access to all of the data in the study and take responsibility for the integrity of the data and the accuracy of the data analysis. All authors reviewed the literature, interpreted the results, and contributed to critical revision of the manuscript.

Study concept and design: Sohn, HW Lee, Park, and Yoon.

Acquisition of data: Sohn, HW Lee, and SH Lee.

Analysis and interpretation of data: Sohn, SH Lee, Lim, HW Lee, MW Lee, and Park.

Drafting of the manuscript: Sohn, HW Lee, Park, and Yoon.

Statistical analysis: CH Park

\section{Acknowledgements}

This systematic review and meta-analysis were developed under the direction of the Korean Liver Cancer Association (KLCA) Committee, which approved the scope of this analysis and provided the peer review. KLCA Committee: Jin Wook Chung, Department of Radiology, Seoul National University Hospital; Chang Wook Kim, Department of Internal Medicine, St. Vincent's Hospital, College of Medicine, The Catholic University of Korea; Jong Man Kim, Department of Surgery, Samsung Medical Center, School of Medicine, Sungkyunkwan University; Ji Hoon Kim, Department of Internal Medicine, Korea University Guro Hospital; Ho Jong Chun, Department of Radiology, College of Medicine, The Catholic University of Korea; Moon Young Kim, Department of Internal Medicine, Yonsei University Wonju College of Medicine; Sang Min Yoon, Department of Radiation Oncology, Asan Medical Center, University of Ulsan College of Medicine; Sang Gyune Kim, Division of Gastroenterology and Hepatology, Department of Internal Medicine, Soonchunhyang University College of Medicine, Bucheon; Won Kim, Department of Internal Medicine, Seoul National University College of Medicine, Seoul Metropolitan Government Boramae Medical Center; Seong Hoon Kim, Center for Liver Cancer, National Cancer Center, Goyang, Korea.

\section{Conflicts of Interest}

The authors have no conflicts to disclose.

\section{SUPPLEMENTARY MATERIAL}

Supplementary material is available at Clinical and Molecular 
Hepatology website (http://www.e-cmh.org).

\section{REFERENCES}

1. Hruby A, Hu FB. The epidemiology of obesity: a big picture. Pharmacoeconomics 2015;33:673-689.

2. Pi-Sunyer $X$. The medical risks of obesity. Postgrad Med 2009;121: 21-33.

3. Renehan AG, Tyson M, Egger M, Heller RF, Zwahlen M. Body-mass index and incidence of cancer: a systematic review and meta-analysis of prospective observational studies. Lancet 2008;371:569-578.

4. Goodwin PJ, Stambolic V. Impact of the obesity epidemic on cancer. Annu Rev Med 2015;66:281-296.

5. Parekh N, Chandran U, Bandera EV. Obesity in cancer survival. Annu Rev Nutr 2012;32:311-342.

6. Wong MC, Jiang JY, Goggins WB, Liang M, Fang Y, Fung FD, et al. International incidence and mortality trends of liver cancer: a global profile. Sci Rep 2017;7:45846.

7. Llovet JM, Zucman-Rossi J, Pikarsky E, Sangro B, Schwartz M, Sherman $M$, et al. Hepatocellular carcinoma. Nat Rev Dis Primers 2016:2:16018.

8. Ratziu V, Bonyhay L, Di Martino V, Charlotte F, Cavallaro L, SayeghTainturier $\mathrm{MH}$, et al. Survival, liver failure, and hepatocellular carcinoma in obesity-related cryptogenic cirrhosis. Hepatology 2002;35: 1485-1493.

9. Ohki T, Tateishi R, Sato T, Masuzaki R, Imamura J, Goto T, et al. Obesity is an independent risk factor for hepatocellular carcinoma development in chronic hepatitis C patients. Clin Gastroenterol Hepatol 2008;6:459-464.

10. Chen CL, Yang HI, Yang WS, Liu CJ, Chen PJ, You SL, et al. Metabolic factors and risk of hepatocellular carcinoma by chronic hepatitis B/C infection: a follow-up study in Taiwan. Gastroenterology 2008;135:111-121.

11. Chen Y, Wang X, Wang J, Yan Z, Luo J. Excess body weight and the risk of primary liver cancer: an updated meta-analysis of prospective studies. Eur J Cancer 2012;48:2137-2145.

12. Rui R, Lou J, Zou L, Zhong R, Wang J, Xia D, et al. Excess body mass index and risk of liver cancer: a nonlinear dose-response metaanalysis of prospective studies. PLoS One 2012;7:e44522.

13. Wang Y, Wang B, Shen F, Fan J, Cao H. Body mass index and risk of primary liver cancer: a meta-analysis of prospective studies. Oncologist 2012;17:1461-1468.

14. Stang A. Critical evaluation of the Newcastle-Ottawa scale for the assessment of the quality of nonrandomized studies in metaanalyses. Eur J Epidemiol 2010;25:603-605.

15. Castillo JJ, Mull N, Reagan JL, Nemr S, Mitri J. Increased incidence of non-Hodgkin lymphoma, leukemia, and myeloma in patients with diabetes mellitus type 2: a meta-analysis of observational studies. Blood 2012;119:4845-4850.

16. Singh S, Singh PP, Singh AG, Murad MH, Sanchez W. Statins are associated with a reduced risk of hepatocellular cancer: a systematic review and meta-analysis. Gastroenterology 2013;144:323-332.

17. Park CH, Kim EH, Roh YH, Kim HY, Lee SK. The association between the use of proton pump inhibitors and the risk of hypomagnesemia: a systematic review and meta-analysis. PLoS One 2014;9:e112558.

18. DerSimonian R, Laird N. Meta-analysis in clinical trials. Control Clin Trials 1986;7:177-188.

19. Higgins JP, Thompson SG, Deeks JJ, Altman DG. Measuring inconsistency in meta-analyses. BMJ 2003;327:557-560.

20. Egger M, Davey Smith G, Schneider M, Minder C. Bias in metaanalysis detected by a simple, graphical test. BMJ 1997;315:629634.

21. Easterbrook PJ, Berlin JA, Gopalan R, Matthews DR. Publication bias in clinical research. Lancet 1991;337:867-872.

22. Higgins JPT, Green GS. Cochrane Handbook for Systematic Reviews of Interventions Version 5.1.0. The Cochrane Collaboration web site, $<$ chttp://handbook-5-1.cochrane.org>. Accessed 5 Mar 2019.

23. Liberati A, Altman DG, Tetzlaff J, Mulrow C, Gøtzsche PC, loannidis $J P$, et al. The PRISMA statement for reporting systematic reviews and meta-analyses of studies that evaluate health care interventions: explanation and elaboration. J Clin Epidemiol 2009;62:e1e34.

24. Calle EE, Rodriguez C, Walker-Thurmond K, Thun MJ. Overweight, obesity, and mortality from cancer in a prospectively studied cohort of U.S. adults. N Engl J Med 2003;348:1625-1638.

25. Batty GD, Shipley MJ, Jarrett RJ, Breeze E, Marmot MG, Smith GD. Obesity and overweight in relation to organ-specific cancer mortality in London (UK): findings from the original Whitehall study. Int J Obes (Lond) 2005;29:1267-1274.

26. Kuriyama S, Tsubono Y, Hozawa A, Shimazu T, Suzuki Y, Koizumi Y, et al. Obesity and risk of cancer in Japan. Int J Cancer 2005;113:148157.

27. Rapp K, Schroeder J, Klenk J, Stoehr S, Ulmer H, Concin H, et al. Obesity and incidence of cancer: a large cohort study of over 145,000 adults in Austria. Br J Cancer 2005;93:1062-1067.

28. N'Kontchou G, Paries J, Htar MT, Ganne-Carrie N, Costentin L, Grando-Lemaire V, et al. Risk factors for hepatocellular carcinoma in patients with alcoholic or viral C cirrhosis. Clin Gastroenterol Hepatol 2006;4:1062-1068.

29. Jee SH, Yun JE, Park EJ, Cho ER, Park IS, Sull JW, et al. Body mass index and cancer risk in Korean men and women. Int J Cancer 2008;123:1892-1896.

30. Joshi S, Song YM, Kim TH, Cho SI. Socio-economic status and the risk of liver cancer mortality: a prospective study in Korean men. Public Health 2008;122:1144-1151. 
31. Inoue $M$, Kurahashi $N$, Iwasaki M, Tanaka Y, Mizokami M, Noda M, et al. Metabolic factors and subsequent risk of hepatocellular carcinoma by hepatitis virus infection status: a large-scale populationbased cohort study of Japanese men and women (JPHC Study Cohort II). Cancer Causes Control 2009;20:741-750.

32. Wang CS, Yao WJ, Chang TT, Wang ST, Chou P. The impact of type 2 diabetes on the development of hepatocellular carcinoma in different viral hepatitis statuses. Cancer Epidemiol Biomarkers Prev 2009;18:2054-2060.

33. Hart CL, Batty GD, Morrison DS, Mitchell RJ, Smith GD. Obesity, overweight and liver disease in the Midspan prospective cohort studies. Int J Obes (Lond) 2010;34:1051-1059.

34. Chao LT, Wu CF, Sung FY, Lin CL, Liu CJ, Huang CJ, et al. Insulin, glucose and hepatocellular carcinoma risk in male hepatitis B carriers: results from 17-year follow-up of a population-based cohort. Carcinogenesis 2011;32:876-881.

35. Hung $\mathrm{CH}$, Lee CM, Wang JH, Hu TH, Chen CH, Lin CY, et al. Impact of diabetes mellitus on incidence of hepatocellular carcinoma in chronic hepatitis C patients treated with interferon-based antiviral therapy. Int J Cancer 2011;128:2344-2352.

36. Borena W, Strohmaier S, Lukanova A, Bjørge T, Lindkvist B, Hallmans $G$, et al. Metabolic risk factors and primary liver cancer in a prospective study of 578,700 adults. Int J Cancer 2012;131:193-200.

37. Chen CT, Chen JY, Wang JH, Chang KC, Tseng PL, Kee KM, et al. Diabetes mellitus, metabolic syndrome and obesity are not significant risk factors for hepatocellular carcinoma in an HBV- and HCV-endemic area of Southern Taiwan. Kaohsiung J Med Sci 2013;29:451459.

38. Li Y, Yatsuya H, Yamagishi K, Wakai K, Tamakoshi A, Iso H, et al. Body mass index and weight change during adulthood are associated with increased mortality from liver cancer: the JACC Study. J Epidemiol 2013;23:219-226.

39. Loomba R, Yang HI, Su J, Brenner D, Barrett-Connor E, lloeje U, et al. Synergism between obesity and alcohol in increasing the risk of hepatocellular carcinoma: a prospective cohort study. Am J Epidemiol 2013;177:333-342.

40. Song X, Pukkala E, Dyba T, Tuomilehto J, Moltchanov V, Männistö S, et al. Body mass index and cancer incidence: the FINRISK study. Eur J Epidemiol 2014;29:477-487.

41. Meyer J, Rohrmann S, Bopp M, Faeh D; Swiss National Cohort Study Group. Impact of smoking and excess body weight on overall and site-specific cancer mortality risk. Cancer Epidemiol Biomarkers Prev 2015;24:1516-1522.

42. Campbell PT, Newton CC, Freedman ND, Koshiol J, Alavanja MC, Beane Freeman LE, et al. Body mass index, waist circumference, diabetes, and risk of liver cancer for U.S. adults. Cancer Res 2016;76:6076-6083.

43. Liu Y, Warren Andersen S, Wen W, Gao YT, Lan Q, Rothman N, et al. Prospective cohort study of general and central obesity, weight change trajectory and risk of major cancers among Chinese women. Int J Cancer 2016;139:1461-1470.

44. Setiawan VW, Lim U, Lipworth L, Lu SC, Shepherd J, Ernst T, et al. Sex and ethnic differences in the association of obesity with risk of hepatocellular carcinoma. Clin Gastroenterol Hepatol 2016;14:309 316.

45. McMahon BJ, Bruden D, Townshend-Bulson L, Simons B, Spradling $P$, Livingston $S$, et al. Infection with hepatitis $C$ virus genotype 3 is an independent risk factor for end-stage liver disease, hepatocelIular carcinoma, and liver-related death. Clin Gastroenterol Hepatol 2017;15:431-437.e2.

46. Nderitu P, Bosco C, Garmo H, Holmberg L, Malmström H, Hammar N, et al. The association between individual metabolic syndrome components, primary liver cancer and cirrhosis: a study in the Swedish AMORIS cohort. Int J Cancer 2017;141:1148-1160.

47. Yang B, Petrick JL, Kelly SP, Graubard BI, Freedman ND, McGlynn KA. Adiposity across the adult life course and incidence of primary liver cancer: the NIH-AARP cohort. Int J Cancer 2017;141:271-278.

48. Brichler S, Nahon P, Zoulim F, Layese R, Bourcier V, Audureau E, et al. Non-virological factors are drivers of hepatocellular carcinoma in virosuppressed hepatitis B cirrhosis: results of ANRS C012 CirVir cohort. J Viral Hepat 2019;26:384-396.

49. Hagström H, Tynelius $P$, Rasmussen F. High BMI in late adolescence predicts future severe liver disease and hepatocellular carcinoma: a national, population-based cohort study in 1.2 million men. Gut 2018;67:1536-1542.

50. Jeong SH, Kim P, Yi SW, Kim YJ, Baeg MK, Yi JJ. Body mass index and gastrointestinal cancer mortality in Korean adults: a prospective cohort study. J Gastroenterol Hepatol 2018;33:1582-1589.

51. Yi SW, Choi JS, Yi JJ, Lee YH, Han KJ. Risk factors for hepatocellular carcinoma by age, sex, and liver disorder status: a prospective cohort study in Korea. Cancer 2018;124:2748-2757.

52. World Health Organization (WHO). Obesity: Situation and trends Global Health Observatory (GHO) data. Geneva: WHO, 2016.

53. Park EJ, Lee JH, Yu GY, He G, Ali SR, Holzer RG, et al. Dietary and genetic obesity promote liver inflammation and tumorigenesis by enhancing IL-6 and TNF expression. Cell 2010;140:197-208.

54. Larsson SC, Wolk A. Overweight, obesity and risk of liver cancer: a meta-analysis of cohort studies. Br J Cancer 2007;97:1005-1008.

55. Pollak M. Insulin and insulin-like growth factor signalling in neoplasia. Nat Rev Cancer 2008;8:915-928.

56. Yoshimoto S, Loo TM, Atarashi K, Kanda H, Sato S, Oyadomari S, et al. Obesity-induced gut microbial metabolite promotes liver cancer through senescence secretome. Nature 2013;499:97-101.

57. McGlynn KA, Petrick JL, London WT. Global epidemiology of hepatocellular carcinoma: an emphasis on demographic and regional variability. Clin Liver Dis 2015;19:223-238. 


\section{CLINCAL And MOLECULAR
HEPATOLOGY}

Volume_27 Number_1 January 2021

58. WHO Expert Consultation. Appropriate body-mass index for Asian populations and its implications for policy and intervention strategies. Lancet 2004;363:157-163.

59. Yi SW, Hong JS, Yi JJ, Ohrr H. Impact of alcohol consumption and body mass index on mortality from nonneoplastic liver diseases, upper aerodigestive tract cancers, and alcohol use disorders in Korean older middle-aged men: prospective cohort study. Medicine (Baltimore) 2016;95:e4876. 